\title{
Ciddi Pulmoner Hipertansiyonlu Komplet Atriyoventriküler Kanal Defekti Onarımundan Sonra Kombine İnhale Nitrik Oksit ve Oral Sildenafil Kullaniması: Vaka Sunumu ve Literature Taraması
} (Combined Use Of inhaled Nitric Oxide and Oral Sildenafil After Repair of Complete Atrioventricular Canal Defect with Severe Pulmonary Hypertension: Report of A Case And Review of Literature) Elif Dem irbaj, Figen Akalin, Alper Kararmaz, Selim isbir, Sinan Arsan, Koray Ak Mermara Üniversitesi Tip Fakültesi Kalp ve Damar Gerrahis, Pediatrik Kardiyoloji" ve Anesteziyoloji ve Reanimasyon AD, istanbul

Correspondence / Yazışma Adresi:

Elif DEMIRBAŞ

S. B. Marmara Üniversitesi Eğitim ve Araştırma Hastanesi, Kalp ve Damar Cerrahisi AD.,

Fevzi Çakmak Mah., Muhsin Yazıcıoğlu cad. No: 10 istanbul

Geliş Tarihi / Received : 11.06.2017

E-mail: elifdemirbas88@hotmail.com

Kabul Tarihi / Accepted : 09.12.2017

\section{Özet}

Amaç: Down sendromu ve komplet tip atrioventriküler septal defekt (KAVSD) tanılarılla takip edilen 12 aylik erkek hasta tam düzeltme operasyonu sonrası postoperatif dönemde pulmoner hipertansif kriz yaşadı. Pulmoner hipertansif kriz inhale nitrik oksit (iNO) tedavisi ile (40-60 ppm) başarılı bir şekilde kontrol edildi. Takiplerinde methemoglobinemi gelişen hastada iNO dozu 24 saat sonra azaltılmak zorunda kalındı $(10 \mathrm{ppm})$. Tedaviye sildenafil tablet $(6 \mathrm{mg} / \mathrm{kg} / \mathrm{gün})$ eklenmesi ile postoperatif pulmoner hipertansif krizler kontrol altına alındı. Konjenital kalp cerrahisinde pulmoner hipertansif krizlerin engellenmesinde ve yan etkilerin kontrol edilmesinde kombine tedaviler etkili yöntemlerdir. ( Sakarya Tip Dergisi 2017, 7(4):245-249)

Anahtar Kelimeler: postoperatif pulmoner hipertansiyon, konjenital kardiyak cerrahi, inhale nitrik oksit, sildenafil

\section{Abstract}

Objective: A 12 month old male baby with diagnoses of Down syndrome and complete atrioventricular canal defect underwent total correction. His early postoperative course was complicated with pulmonary hypertensive crises. It was initially treated by 40-60 ppm inhaled nitric oxide (iNO), but we had to decrease the dosage because of serum increased methemoglobin levels after 24 hours of treatment (10 ppm). We added oral sildenafil sitrate as a combination therapy $(6 \mathrm{mg} / \mathrm{kg} / \mathrm{day})$ which was seemed to be effective in controlling pulmonary hypertensive crises. Combined regimens like iNO and sildenafil for postoperative pulmonary hypertensive crises are beneficial in terms of reducing the dosage of iNO and preventing rebound pulmonary hypertension. ( Sakarya Tip Dergisi 2017, 7(4):245-249 )

Keywords postoperative pulmonary hypertension; congenital cardiac surgery; inhaled nitric oxide; sildenafil. 


\section{Giriş}

Komplet tip atrioventriküler septal defekti (KAVSD) gibi geniş sol sağ şantlı doğumsal kalp hastalığı olan çocuklarda pulmoner sistemde artmış akıma bağlı olarak erken dönemde ciddi pulmoner hipertansiyon (PHT) gelişme riski yüksektir. Down sendromlu hastalarda görülen pulmoner sisteme ait bir takım yapısal problemlerin, bu hastalarda KAVSD'e bağlı PHT gelişim riskini önemli oranda arttırdığı bilinmektedir ${ }^{1}$. Bu hastalarda total cerrahi düzeltme sonrası erken dönemde mortaliteyi arttıran en önemli etken PHT krizleri ve buna bağlı gelişen akut sağ kalp yetmezliği tablosudur ${ }^{2}$. Son yıllarda, erken dönemde cerrahi tedavi yapılması ve peroperatif dönemde uygulanan inhale nitrik oksid (iNO) ve endotelin reseptör antagonistleri gibi bazı ajanların sık kullanılması postoperatif PHT krizlerin görülme sıklığında azalmaya sebep olmuștur. Özellikle iNO kesilmesinden sonra ortaya çıkan rebound PHT krizleri, bu hastalarda kombine tedavilerin kullanılması gerekliliğini doğurmaktadır ${ }^{3}$. Bu yazımızda, KAVSD'li Down sendromu olan bir hastanın cerrahi onarım sonrası başarılı bir şekilde kombine iNO ve oral sildenafil kullanımı ile tedavi edilmesi sunulmuştur.

\section{Vaka Sunumu}

Down sendromu ve KAVSD tanılarılla takip edilen 12 aylık erkek hasta tam düzeltme için kliniğimize refere edildi. Hastanın özgeçmişinde sık tekrarlayan akciğer enfeksiyonları ve konjenital hipotroidi mevcut idi. Yapılan ilk değerlendirmede ileri derecede büyüme gelişme geriliği saptandı (boy: $70 \mathrm{~cm}$ kilo:6.900 kg, 3 persantilin altında). Fizik muayenede solunum sesleri bilateral kaba, prekordiyumda hiperaktivite, sol üst sternal bölgede belirgin 2-3/6 sistolik ejeksiyon üfürümü ve hepatomegali saptandı. Akciğer grafisinde kardiyotorasik indekste artıs $(0.60)$ ve pulmoner vasküler yapılarda belirginleşme, elektrokardiyografide normal sinüs ritmi (125/dak) ve kardiyak aksta sola kayma tespit edildi. Laboratuvar incelemesinde anormal bir bulguya rastlanmadı. Transtorasik ekokardiyografide tek AV kapak (Rastelli tip A, geniş interventriküler ve interatrial defekt), dengeli sağ ve sol ventrikül ve ciddi PHT tespit edildi (sağ kalp kateterizasyonu ile pulmoner arter (PA) basıncı $65 / 35 / 45 \mathrm{mmHg}$ ve pulmoner vasküler rezistans 5.8 Wood Ünite). Sol ve sağ AV kapak yetmezlikleri hafif olarak derecelendirildi.

Tam düzeltme operasyonunda mediyan sternotomi insizyonu ile gerçekleştirildi. Tam düzeltme işlemi modifiye tek yama tekniği kullanılarak uygun şekilde hazırlanan perikard yama ile yapıldı. Sol AV kapak üzerindeki kleft tek tek atılan 6/0 prolen ile kapatıldı. Baypas sonrası direkt pulmoner arter üzerinden ölçülen basınç 55/40/37 mmHg idi. Sağ ventrikül üzerinden PA kateteri yerleştirildi.

Postoperatif yoğun bakımda hasta derin sedasyon (midazolam, morfin ve fentanil) ve volüm kontrollü ventilasyon ile takip edildi. ỉkili inotrop (dopamin $5 \mathrm{mcg} / \mathrm{kg} / \mathrm{dk}$ ve milrinon $0.5 \mathrm{mcg} / \mathrm{kg} /$ $\mathrm{dk}$ ) infüzyonu verildi. iNO 20 ppm dozundan başlandı. Ölçülen PA basınç değerleri 55-60/30-36 mmHg arasında seyretti. iNO dozu kademeli olarak arttırılarak 60 ppm'e kadar çוkıldı. Takiplerinde görülen maksimum PA basıncı 30/18 mmHg olarak saptandı. Ancak hastanın kan gazı takiplerinde methemoglobin (met-Hb) düzeyi hematokrit değerinin \%15'ini geçmesi üzerine (met-Hb: \%6) iNO dozu azaltıldı (30 ppm). Yapılan kontrol transtorasik ekokardiyografisinde sağ ve sol AV kapaklarda minimal düzeyde yetersizlik tespit edildi. Yamadan kaçak tespit edilmedi. Postop 1. günde PA basınçlarının 100/60 mmHg'ya kadar yükselmesi nedeniyle iNO düzeyi tekrar arttırıldı. Hastanın methemoglobin düzeyinde yeniden artış meydana gelmesiyle iNO düzeyinin azaltılmasıyla beraber hastaya nazoduodenal (ND) yolla sildenafil tablet tedavisi başlandı (6 mg/kg/gün) ve iNO desteği 30 ppm'de tutuldu. Pulmoner hipertansif kriz ile birlikte oksijen ve inotrop ihtiyacında artış oldu. Oliguri gelişmesi üzerine hastaya furosemid infüzyonu (1 mg/saat) başlandı. Hastanın taşikardik seyretmesi, kalp hızı 180/dk'ya kadar yükselmesi nedeniyle digoksin tedavisi başlandı. Sildenafil tedavisinin 5.saatinde PA basıncı 60/35 mmHg değerlere düştü. Postop 3. günde hastanın PA basınçları progresif olarak azaldı (45/20 $\mathrm{mmHg}$ ) ve oksijen ihtiyacı \% 60 idi. Postop 4 . günde hemodinamisi stabil olan hastanın inotrop dozları kademeli olarak azaltıldı ve hastanın dopamin ve milrinon infüzyonları stoplandı. Hastanın kan gazı parametleri takip edilerek PEEP üstü basıncı kademeli olarak azaltıldı. (PEEP: 6 cmH2O PEEP üstü:13 cmH2O) Postop 5. günde genel durumu stabil seyreden ve PA basınçları 40-45/20-24 $\mathrm{mmHg}$ civarında seyreden hastanın PA kateteri çekildi. Sonrasında oksijen ihtiyacı azalan hasta ventilator basınç desteği de azaltılarak postop 8. günde ekstübe edildi ve nazal $5 \mathrm{lt} / \mathrm{dk}$ oksijen ile takibe alındı. Postop 9. Günde oksijen ihtiyacı 2 lt/dk düşen hastanın sildenafil dozu azaltıldı ( $0.5 \mathrm{mg} / \mathrm{kg} /$ gün) ve hasta postop 11 . günde 
servise transfer edildi. Servis takiplerinde ek sıkıntısı olmayan hasta antibiyoterapisi tamamlandıktan sonra taburcu edildi.

\section{Tartışma}

Komplet tipte AVSD özellikle sıklıkla kalp yetmezliği ve ciddi pulmoner hipertansiyon kliniğiyle karşımıza çıkan bir konjenital kalp hastalğıdır. Ciddi pulmoner hipertansiyon krizleri, pediatrik kardiyak cerrahi sonrası görülebilmekte ve vakaların pekçoğunda etkin tedavi ile başarılı sonuçlar alınmaktadır. Lars Lindberg ve arkadaşlarının yaptığı 1349 hastalık çalışmada pediatrik kardiyak cerrahi sonrası takip edilen hastalarda ciddi pulmoner hipertansiyon görülme oranı \% 2 (27 hasta) olarak saptanmıştır. Pulmoner hipertansiyon gelişen hastaların \% 7.4 kadarı operasyondan sonra erken dönemde (30 gün içerisinde) kaybedilmiştir. Operasyon sonrası 1 yıllık mortalite ise $\% 11$ olarak saptanmışı ı ${ }^{2}$. Postoperatif dönemde bu hastalarda pulmoner hipertansif kriz gelişme riski mevcuttur. Hopkins ve arkadaşları tarafından yapılan klinik bir çalışmada ise, konjenital kalp hastalığı nedeniyle kardiyak cerrahi yapılan PHT açısından yüksek riskli çocuklardan; 20 hastanın 11'inde bir ya da daha fazla pulmoner hipertansif kriz gelişmiştir4. Pulmoner hipertansif kriz ise bu riskli gruptaki hastaların hastane yatış süresinde artışa ve uzun süre entübe kalmalarına bağlı morbiditenin artmasına neden olmaktadır.

Pulmoner hipertansiyon açısından riskli olan hastalarda entübasyon süresi uzamaktadır. Bu hastalarda yakın monitorizasyon gerekli olup pulmoner hipertansif kriz gelişmesi halinde artmış sedasyon, artmış oksijen desteği, CO2 düzeyinin 25 mmHg' ya kadar düşürülmesi, intravenöz sodyum nitroprussid ve iNO tedavisi en fazla bilinen tedavi seçenekleridir. Pulmoner hipertansiyon tedavisinde en sık kullanılan ajan iNO'dur. Oldukça etkin bir tedavi yöntemi olmakla birlikte iNO tedavisinin yan etkileri ve kesildikten sonra görülen rebound pulmoner hipertansiyon nedeniyle günümüzde standart uygulamalara ek olarak pulmoner vazodilatör ajanların tek başına ya da kombine olarak kullanılması gündeme gelmiştir ${ }^{5}$.

Pulmoner hipertansiyon tedavisinde pek çok farmakolojik ajan bulunmaktadır. Avrupa Kalp Cemiyetinin (ESC) 2015 yllında yayınladığı pulmoner hipertansiyon kılavuzlarına göre başlıca tedavi seçenekleri şöyle sıralanmaktadır ${ }^{6}$. 1. Kalsiyum kanal blokerleri: Vazoreaktivite testine pozitif yanıt veren hastalarda akut vazodila- tasyon yaparak etki gösteren KKB'lerinin başılıcaları nifedipin ve diltiazemdir. Görece bradikardik olan hastalarda nifedipin, taşikardik olan hastalarda ise diltiazem tercih edilmekle birlikte pediatrik vakalarda sınırlı hasta popülasyonu üzerinde etkilidir. 2. Endotelin reseptör bloklerleri (bosentan, sitaksentan,ambrisentan): Endotelin endotel hücreleri tarafından yapılan ve güçlü vazokonstriksiyon yapan aynı zamanda mitojen bir ajandır. Endotelin reseptör blokerleri A ve B tipi olmak üzere reseptör blokajı ile vazodilatasyon sağlar. 3. Fosfodiesteraz 5 inhibitörleri (sildenafil, tadalafil) : cGMP yıkımını sağlayan enzim olan fosfodiesteraz 5 enzimini bloke eden ajanlar hücre içi yolaklarda nitrik oksit (NO) yapımını artıırarak vazodilatasyona sebep olur.

Sildenafil sitrat, selektif ve potent bir fosfodiesteraz 5 (PDE-5) enzimi inhibitörüdür. Bu enzim esas olarak peniste kavernöz korpüsde yüksek konsantrasyonda bulunmakla birlikte, vasküler düz kaslar, organ düz kasları ve trombositlerde de bulunur. Sildenafil, siklik guanozin monofostat (cGMP) spesifik PDE-5 enzimini inhibe ederek, vazodilatasyon yapan cGMP seviyesini yükseltir. PHT'lu hastalarda bu etki pulmoner yatakta da ortaya çıkar ve PA basıncı düşer (7). Pediatrik kardiyak cerrahi sonrası hem tek başına hem de diğer ajanlarla kombine olarak kullanılmaktadır.

4. Prostasiklinler (epoprostenol,iloprost, treprostanil,beroprost): Prostasiklin ağılıklı olarak endotel hücresinde yapilır ve bütün damar yataklarında vazodilatasyona neden olur.

5. Nitrik oksit: Membranları kolayca geçebilme özelliği olan oldukça lipofilik bir moleküldür. Özellikle nöronlar ve damar düz kas hücre membranında bulunan guanilat siklazı aktive eder. NO bir kez sentezlendikten sonra hızla hedef dokulara yaylır ve hücre içinde guanilat siklaz enzimini aktive ederek düz kas kasılmasını sağlayan cGMP miktarını artııır. Oluşan bu biyokimyasal olaylar düz kas kasılması, vasküler tonüs ve kan akışının düzenlenmesinde önemli rol oynar. NO aynı zamanda trombositler içindeki çözülebilir guanilat siklaz aktivitesini de artırarak trombosit adezyon ve agregasyonunu azaltır. Ayrıca mikroorganizmaların mitokondriyal proteine bağlı demir bileşikleriyle reaksiyona girip DNA sentezini bozarak ölmelerine yol açar ve savunma sisteminde rol oynar. Yarılanma ömrü çok kısadır ve solüsyonlarda hızlı okside olarak nitrit 
(NO2) ve nitrata (NO3) dönüşür. İnsan vücudunda NO, hemoglobine bağlandığında inaktive olur . Bu kadar hızlı inaktive olması etkilerini lokalize kılan en önemli faktördür ${ }^{8}$. Johannes Breuer ve ark tarafından yapılan 28 hastalık çalışmaya göre iNO tedavisi pulmoner arter basınçlarında \% 48 kadar bir azalma sağlamakta ve olguların \% 98'inde pulmoner hipertansiyonu azaltmaktadı ${ }^{9}$. iNO tedavisi KAVSD nedeniyle opere edilen hastalarda erken postoperatif dönemde mortaliteyi azaltmaktadır ${ }^{10}$.

İnhale NO tedavisinin bilinen en önemli yan etkisi methemoglobinemidir. Bu yan etkiler 80 ppm'den düşük dozlarda nadiren ortaya çıkmasına rağmen doku hiposisine neden olabilir ${ }^{11}$. Ayrıca bilinen bir başka yan etki de endotelin 1 reseptörlerinde oluşan down regülasyona bağlı olduğu düşünülen rebound PHT'dur ${ }^{11}$. PHT nedeniyle postoperatif iNO tedavisi başladığımız olgumuzda kan gazı takiplerinde methemogobinemi gelişmesi nedeniyle iNO dozunu azaltmak durumunda kaldık. iNO tedavisinde doz azaltmaya gitmemizin ardından hastada gelişen pulmoner hipertansif kriz nedeniyle hemodinamisinde bozulma meydana gelmesiyle iNO tedavisinin dozunu arttırma yoluna gitmemize rağmen uzun dönemde tedavi devamı yan etkileri nedeniyle mümkün olmaması üzerine hastanın tedavisine sildenafil eklendi. Sildenafil tedavisi başlandıktan sonra iNO dozu mümkün olan maksimum düzeyden verildi. Kombine tedavi ile pulmoner arter basınçları normale dönen hasta solunum parametrelerinin düzelmesiyle sıkıntısız ekstübe edildi.

Tüm bu veriler ışığında özellikle bizim hastamızda olduğu gibi sistemik kan basıncına yakın değerlerde ağı PHT'u olan olgularda iNO tedavisinin yanına ikinci bir ajan eklenmesi gerekliliği göz önünde bulundurulmalıdır.

Kombinasyon tedavisinin amacı gerek monoterapinin yeterli etkinlikte olmaması gerekse bizim vakamızda olduğu gibi yan etkiler dolayısıyla monoterapinin etkin dozda verilememesidir ${ }^{12}$. Lee ve arkadaşları tarafından yapılan retrospektif bir çalışmada iNO'dan ayrılmada güçlük çekilen 7 hastada sildenafil kullanımı sonrası başarılı sonuçlar bildirilmiştir ${ }^{13}$.

Sonuç olarak hem iNO tedavisinin yan etkilerinden korunmak amacıyla hem de iNO tedavisinin kesilmesi sonrasında oluşan re- bound pulmoner hipertansiyonun önlenmesi amacıyla tek başına iNO tedavisi yerine iNO ve sildenafil gibi kombine tedavilerin daha etkili olabileceğini düşünmekteyiz. Ancak kombine tedavi, monoterapiye yanıt vermeyen olgularda kullanılmakla birlikte tedavinin yaşam süresi ne katkısını gösteren yeterince çalışma bulunmamaktadır. Ayrıca kombinasyon tedavisine geçişte ilaç tercihi ya da kombinasyon tedavisinin başlangıç zamanı gibi konuların da araştırılması gerekmektedir. 
1. Sungur M, Ocal B, Oguz D, Karademir S, Karakurt C, Senocak F. Plasma endothelin 1 and nitrate levels in Down's syndrome with complete atrioventricular septal defect associated pulmonary hypertension: a comparison with non-Down's syndrome children. Eur J Pediatr 2009; 168:593-7.

2. Lindberg L, Olsson AK, Jögi P, Jonmarker C. How common is severe pulmonary hypertension after pediatric cardiac surgery ?. J Thorac and Cardiovasc Surg 2002; 123:1155-63.

3. Mossad EB. Pro:Intraoperative use of nitric oxide for treatment of pulmonary hypertension in patients with congenital heart disease is effective: $J$ Cardiothorac and Vasc Anesth 2001; 15:259-62.

4. Hopkins RA, Bull C, Haworth SG, Level MR, StarkJ. Pulmonary hypertensive crises following surgery for congenital heart defects in young children. EurJ Cardiothorac Surg.1991; 5:628-34.

5. Sasmazel A, Adademir T, Baysal A, Öner N, Özkökeli M, Yılmaz E, et al. Doğuştan kalp cerrahisi sonrası inhale nitrik oksit tedavisinin kesilmesine yardımcı oral sildenafil kullanımı: Klinik deneyimlerimiz . Türk Göğüs Kalp Damar Cerrahisi Dergisi, Ekim 2011; 4:518-523.

6. Galie N, Humbert M, Vachiery J, Gibbs S, Lang I, Torbicki A, et al. 2015 ESC/ERS Guidelines for the diagnosis and treatment of pulmonary hypertension: The Joint Task Force for the Diagnosis and Treatment of Pulmonary Hypertension of the European Society of Cardiology (ESC) and the European Respiratory Society (ERS): Endorsed by: Association for European Paediatric and Congenital Cardiology (AEPC), International Society for Heart and Lung Transplantation (ISHLT). Eur Heart J 2016; 37 (1): 67-119

7. Diker E, Aydoğdu S. Oral sildenafil sitratın sıradışı bir kullanımı. Arch Turk Soc Cardiol 2002; 30:208-210

8. Özkan M, Yüksekol I. Nitrik Oksit ve Akciğerler. Türk Toraks Cerrahisi Dergisi, Nisan 2003; 1: 088-094

9. Breuer J, Prein W, Gebhardt S, Knies R, Sieverding L, Baden W,Apitz J. Inhaled Nitric oxide treatment of children with pulmonary hypertension after cardiac surgery. Progress in Pediatric Cardiology, March 1999; 9:73-83

10. Journois $D$, Baufreton $C$, Mauriat $P$, Pouard $P$, Vouhei $P$, Safran D. Effects If inhaled nitric oxide administration in patients operated for correction of atrioventricular canal defects. Chest, November 2005; 128:3537-44.

11. Ichinose F, Roberts JD, Zapol WM. Inhaled Nitric Oxide-A Selective Pulmonary Vasodilator: Current Uses and Therapeutic Potential. Circulation, June 2004; 109:3106-11.

12. Hill NS, Roberts KR, Preston IR. Postoperative Pulmonary Hypertension:Etiology and Treatment of a Dangerous Complication. Respir Care, July 2009; 54(7):958-68.

13. Lee JE, Hillier SC. Knoderer CA. Use of sildenafil to facilitate weaning from inhaled nitric oxide in children with pulmonary hypertension following surgery for congenital heart disease. J Intensive Care Med. Sep-Oct 2008; 23:329-34. 